\title{
The social determinants of multimorbidity in South Africa
}

\author{
Olufunke Alaba ${ }^{1}$ and Lumbwe Chola ${ }^{2^{*}}$
}

\begin{abstract}
Introduction: Multimorbidity is a growing concern worldwide, with approximately 1 in 4 adults affected. Most of the evidence on multimorbidity, its prevalence and effects, comes from high income countries. Not much is known about multimorbidity in low income countries, particularly in sub-Saharan Africa. The aim of this study was to determine the prevalence of multimorbidity and examine its association with various social determinants of health in South Africa.

Method: The data used in this study are taken from the South Africa National Income Dynamic Survey (SA-NIDS) of 2008. Multimorbidity was defined as the coexistence of two or more chronic diseases in an individual. Multinomial logistic regression models were constructed to analyse the relationship between multimorbidity and several indicators including socioeconomic status, area of residence and obesity.

Results: The prevalence of multimorbidity in South Africa was $4 \%$ in the adult population. Over $70 \%$ of adults with multimorbidity were females. Factors associated with multimorbidity were social assistance (Odds ratio (OR) 2.35; Confidence Interval (Cl) 1.59-3.49), residence (0.65; 0.46-0.93), smoking (0.61; 0.38-0.96); obesity (2.33; 1.60-3.39), depression (1.07; 1.02-1.11) and health facility visits $(5.14 ; 3.75-7.05)$. Additionally, income was strongly positively associated with multimorbidity. The findings are similar to observations made in studies conducted in developed countries.
\end{abstract}

Conclusion: The findings point to a potential difference in the factors associated with single chronic disease and multimorbidity. Income was consistently significantly associated with multimorbidity, but not single chronic diseases. This should be investigated further in future research on the factors affecting multimorbidity.

Keywords: Multimorbidity, South Africa, Social determinants of health

\section{Background}

Multimorbidity can be defined as the simultaneous occurrence of two or more chronic health conditions in the same person, without defining a primary disease [1-3]. Often, the study of multimorbidity is associated with aging [3]. However, there has been an increase in the prevalence of multimorbidity among people below the age of 65 years [4]. It is estimated that in developed countries, about 1 in 4 adults experience multimorbidity, with half of older adults having 3 or more chronic conditions [3,5]. Multimorbidity impacts negatively on individuals and the health system as a whole. It is associated with increased mortality, poor quality of life and an increased demand on healthcare

\footnotetext{
* Correspondence: lumbwechola@hotmail.com

${ }^{2}$ Health Systems and Services Research Unit, Division of Community Health, Stellenbosch University, Cape Town, South Africa

Full list of author information is available at the end of the article
}

utilisation, all of which place a strain on healthcare resources [6,7]. Persons with multimorbidity may also be at risk of sub-optimal care due to the high likelihood of obtaining conflicting advice on treatment and care $[8,9]$. It is often difficult to obtain meaningful medical advice on combinations of chronic conditions faced by an individual due to the pure single-disease outlook prominent in most health systems.

The burden of multimorbidity has typically been studied in high income countries, where its prevalence and socioeconomic determinants have been established [2] as well as its impact on healthcare utilization [10], with very few of these studies conducted in low and middle income countries [11-13]. As such, the prevalence and determinants of multimorbidity in sub-Saharan Africa is relatively unknown. This is despite the fact that obesity, a primary
C Biomed Central

(c) 2013 Alaba and Chola; licensee BioMed Central Ltd. This is an Open Access article distributed under the terms of the Creative Commons Attribution License (http://creativecommons.org/licenses/by/2.0), which permits unrestricted use, distribution, and reproduction in any medium, provided the original work is properly cited. 
predisposing risk factor underlying chronic diseases, is on the increase [14], in developing countries as well as several other chronic non-communicable diseases [15,16]. The increased burden of non-communicable diseases in subSaharan Africa has potential implications on the health system and resource allocation [17]. Managing multimorbidity is thus very important. However, this becomes increasingly difficult to do with the absence of adequate information to influence priority setting and decision making. There is thus need to understand the root causes of disease and to provide evidence of the factors affecting both single chronic diseases and multimorbidity [18].

This study seeks to determine the prevalence of multimorbidity in South Africa, and to examine its association with various social determinants of health. In addition to age and gender, structural and intermediary determinants such as socioeconomic status, psychosocial, and environmental factors that affect health are assessed. The WHO social determinants of health framework is used to guide the analysis.

\section{Theoretical framework}

Many researchers have analysed the social determinants of health, showing how factors such as marital status, socioeconomic status, education and smoking influence chronic diseases [14,19], however studies on the social and economic factors associated with multimorbidity are limited $[4,20,21]$. In this paper, we use the Commission on Social Determinants of Health (CSDH) model to examine the determinants of multimorbidity [22]. The model posits that besides inherent genetic factors, other factors including the living and working environment, life events, behavioural risk factors and socioeconomic status may affect the occurrence and intensity of disease. The model uses structural and intermediary determinants to explain factors influencing health and wellbeing.

Structural determinants include factors related to socioeconomic status, such as education, income and occupation and the broader social opportunity structures, such as social class and gender, which determine access to health care [4]. Generally, economically deprived individuals are more likely to experience the worst health outcomes [23]. A recent study showed that socioeconomic deprivation is associated with an increased likelihood of multimorbidity. Addressing the structural determinants of health is therefore important to creating an enabling environment for equitable delivery of healthcare.

Intermediary determinants of health include material circumstances of living and working conditions and food availability, biological and psychosocial factors. Understanding intermediary factors is particularly important for improving health systems, because these factors address access to health and social participation, which differ by age, gender and ethnicity. An ecological study by Kwachi, et al. found social allegiances and poor relational trust to be linked to mortality [24]. Social capital serves as an important asset that helps to strengthen health information dissemination and improves access to healthcare [25].

\section{Methods \\ Data}

Data were taken from the first wave of the 2008 South African National Income Dynamics Study (SA-NIDS). This cross-sectional study was undertaken by the South African Labour and Development Research Unit (SAL DRU) based at the University of Cape Town (UCT). A stratified, two-stage cluster sample design was employed in sampling the households to be included in the study. The explicit strata in the Master Sample were the 53 district councils (DCs) in the country. The sample was proportionally allocated to the strata based on the Master Sample DC PSU allocation. A total of 400 Primary Sampling Units (PSUs) were randomly selected within the strata. Within each PSU, 8 non-overlapping samples (clusters) of dwelling units were systematically drawn. The SA-NIDS provides baseline data on a sample of 28,247 individuals including children from 7,301 households, out of a possible 10,642 households, a response rate of $69 \%$. The sample consisted of 16,800 adults from age 15 years. Study approval was granted by the Ethics Committee of the University of Cape Town. A detailed report on the SANIDS methodology is provided elsewhere [26]. Household and adult questionnaires were administered to all household members aged 15 years and older. The study documents the dynamic structure of household members and changes in their incomes, expenditures, assets, access to services, education, health and other dimensions of wellbeing. For this analysis, we applied a cut off age of 18 years, given that multimorbidity was not observed among respondents below 18 years. Thus, observations under the age of 18 years were dropped. Missing data on social and economic indicators, body mass index, age, sex and race and multimorbidity were deleted. The final sample used in the analysis was therefore $n=11,638$.

\section{Measures \\ Dependent variable}

In the SA-NIDS, respondents were asked to state whether or not they currently had one or more of several chronic health conditions including tuberculosis (TB), high blood pressure, diabetes or high blood sugar, stroke, asthma and cancer as confirmed by a doctor. In the analysis, these health conditions were combined to create a summative index of multi-morbidity ranging from 0 to 4 . A categorical variable was then created to indicate: 0 ) no chronic disease, 1) presence of 1 chronic disease and 2) multimorbidity (i.e. presence of 2 or more chronic diseases). 


\section{Independent variables}

Structural determinants Based on the CSDH framework, age, gender, race, education, employment, income, social assistance and residence were structural determinants of health. We hypothesized that structural determinants were directly or indirectly associated with multimorbidity. We expected age, gender, race, income and social assistance to be positively associated with multimorbidity. In the literature, multimorbidity is shown to increase with age and females usually have higher multimorbidity prevalence than males [27]. We also expected income and race to be positively associated with multimorbidity. It has been shown that persons from affluent communities and the well to do in most African countries are more likely to experience chronic diseases [19]. However, living in a rural area, employment and education have been shown to be positively related to self-reported health $[28,29]$, thus we expected these variables to be negatively associated with multimorbidity. Social assistance on the other hand was expected to be positively associated with multimorbidity, since the recipients, who are expected to be extremely poor, may be prone to non-communicable diseases such as mental distress and obesity, which are predisposing factors for chronic disease [19].

Age was measured in single years from 18 years and included as a continuous variable. Gender was categorized as 1 - female and 0 - male. Race was a categorical variable with 1 - African, 2 - Coloured, 3 - Asian/Indian and 4 - White. Education was measured in years of schooling and categorised as 1 - no education, 2 - primary (1-7 years), 3 - secondary (8-12 years) and 4 - tertiary (13+ years). Employment included those in both formal and informal employment and was dichotomised into (1) employed and (0) unemployed. The household income was categorically coded into 5 quintiles, ranging from the poorest to the richest quintile as given in the data set. Social assistance was measured by summing the number of government grants available to individuals. This was categorised into 0) no grant, 1) receipt of grant. We included the rural/urban dichotomy to indicate place of residence with (1) rural and (0) urban.

Intermediary determinants In the CSDH framework, health and psychosocial factors are considered to be intermediary factors. We included risk factors of multimorbidity, smoking and obesity, depression, health facility visits and civic participation as intermediary factors. We anticipated that all the intermediary factors would be positively associated with multimorbidity.

Smoking was included as a dichotomous variable indicating 0) non-smoker and 1) smoker. Obesity was estimated from the weights and heights of respondents in the SA-NIDS survey. To measure obesity, we used the body mass index (BMI) as weight (measured in kilograms, kgs) divided by height squared (metres $-\mathrm{m}^{2}$ ), which were measured by enumerators during data collection. A BMI greater than 30 was considered to be obese. A binary variable was thus generated, 1 if obese and 0 otherwise. We expected a positive relationship with multimorbidity as observed with chronic diseases [30]. The variable 'Depression' was created using the self-reported Centre for Epidemiologic Depression (CES-D) 10 item scale, which has been validated and shown to correlate with the 20-item CES-D scale [31]. The CES-D is designed to measure depression in the general population. In the SA-NIDS, respondents were asked to indicate on a scale from 1 (rarely) to 4 (all the time) how they felt in the week prior to the interview with regard to the following: whether the respondent felt unusually bothered by things; had trouble concentrating; felt depressed; felt that doing things was an effort; was hopeful about the future; was fearful; had restless sleep; was happy; felt lonely; or could not get going. The depression score was created as a summative index of the 10 items, ranging from 0 to 30 , reflecting an increase in depression with increasing score. We used the Cronbach's Alpha test to check the reliability of the scale. (This gave a scale reliability coefficient of 0.79). A dichotomous variable was created indicating whether an individual had a health facility contact within the month prior to the survey $(1-$ yes and $0-$ no). This was included to control for healthcare utilization [10] because it is expected that the use of health care facilities increases with high prevalence of multimorbidity. Emerging evidence shows that individual level social capital which defines how people connect with others in their environment is a strong positive social determinant of health $[32,33]$. In the SA-NIDS, respondents were asked to indicate whether they belonged to one or more of 18 associations. This was used as an indicator of individual level social capital, with a dichotomous variable created to reflect whether (1) an individual belonged to at least one group or (0) did not belong to any group.

\section{Data analysis}

All statistical analyses were done in STATA software version 12 (Stata Corp. Inc. TX, USA). Clustering and survey design effects were accounted for using Stata's stratified multi-stage design feature. A multinomial logistic regression analysis was used to evaluate the unadjusted association of each variable with 1 chronic disease and 2 or more chronic diseases (multimorbidity); the reference category was no chronic disease. Additionally, a multinomial logistic regression was used to control for potentially confounding effects of other variables, with the analysis done in steps guided by the $\mathrm{CSDH}$ framework. The multinomial logistic regression was thus performed in 4 steps, with step 1 being the univariate or 
unadjusted analysis, step 2 included structural variables only, step 3 included intermediary variables only, and step 4 included all the variables. Effect modification was tested, and since no interaction terms were statistically significant at $\mathrm{p}=0.05$, they were not included in the analysis.

\section{Results}

The sample consisted of 11,638 adults, of which most were females (61\%), Table 1 . The majority of the respondents had secondary (54\%) and only a few had tertiary (6\%) education. The proportion of unemployed was $63 \%$, with over $40 \%$ receiving social assistance in the form of government grants. The mean age (Standard Deviation $\mathrm{SD})$ was 40 years (16.7). The mean (SD) depression score was 8.4 (4.8). The mean (SD) monthly household income was $\mathrm{R} 3,123(6,413)$. About $53 \%$ of respondents lived in rural areas, $22 \%$ were smokers, $26 \%$ were obese and $27 \%$ had had more than 1 or more hospital visits.

Approximately $21 \%$ of the respondents had at least 1 chronic disease and $4 \%$ had experienced 2 or more chronic diseases i.e. multimorbidity. Among the chronic diseases, diabetes ranked as the highest contributor to multimorbidity with $56 \%$, followed by asthma (23.4\%), stroke (9.2\%), cancer (5.8\%) and blood pressure (5.6\%). Figure 1 shows the contribution of chronic diseases to multimorbidity by gender. For both men (54\%) and women (57\%), diabetes was the highest contributor to multimorbidity. The least contributor among women was blood pressure (4\%), and cancer for men (5\%).

As shown in Table 1, the majority of respondents with multimorbidity were females (74\%). Most of the persons with multimorbidity had less than secondary education (69\%), were unemployed (76\%), were recipients of at least 1 government grant (78\%), and lived in urban areas (51\%). About 18\% were smokers, $49 \%$ were obese and $68 \%$ had at least 1 hospital visit in the 30 days prior to the interview.

Table 2 shows the results of the univariate and multivariate multinomial logistic regression of factors associated with single and multimorbidity, relative to the base category no disease. In step 1 (univariate), all variables except smoking and civic participation were significantly associated with 1 chronic disease. The variables not associated with 2 or more chronic diseases (multimorbidity) were residence and civic participation. In comparison to 1 chronic disease, almost all the odds ratios (ORs) of variables associated with multimorbidity were significantly elevated. For example, the OR of health facility visits was 4.94 and 8.05 for 1 chronic disease and multimorbidity, respectively.

In step 2 (structural factors), the variables significantly associated with 1 chronic disease were age $(1.18$; 1.14 $1.21)$, gender $(1.53 ; 1.30-1.80)$, employment $(0.70 ; 0.58$ $0.86)$, social assistance $(1.48 ; 1.22-1.80)$ and residence
(0.65; 0.52-0.81). Employment and residence were negatively associated with 1 chronic disease. This pattern was similar to that observed for multimorbidity, with age $(1.44 ; 1.32-1.57)$, gender $(1.95 ; 1.39-2.73)$, employment (0.65; 0.42-0.99), social assistance $(2.84 ; 1.88-4.30)$ and residence $(0.59 ; 0.42-0.82)$ being the significant factors. Additionally, household income was strongly associated with multimorbidity, a positive relationship implying that persons from high income households were more likely to have 2 or more chronic diseases.

In step 3 (intermediary factors), smoking, which was a significant univariate factor for multimorbidity, was not associated with neither 1 nor 2 or more chronic diseases. Civic participation was also consistently not associated with morbidity. The variables associated with both 1 chronic disease and multimorbidity were obesity, depression and health facility visits.

When all the variables were included in the analysis in step 4 (full model), gender, race, education, income, smoking and civic participation were not associated with 1 chronic disease. While employment was strongly associated with 1 chronic disease (0.72; 0.58-0.90), it was not significant for multimorbidity. Income was also strongly associated with multimorbidity, but not 1 chronic disease. Whereas smoking was not a factor with 1 chronic disease, it was negatively associated with multimorbidity $(0.61 ; 0.38-0.96)$. Other variables significantly associated with multimorbidity were age $(1.38 ; 1.25-1.51)$, social assistance $(2.35 ; 1.59-3.49)$, residence $(0.65 ; 0.46-0.93)$, obesity $(2.33$; 1.60-3.39), depression $(1.07 ; 1.02-1.11)$ and health facility visits $(5.14 ; 3.75-7.05)$.

\section{Discussion}

This paper used data from a national household survey to examine the prevalence of multimorbidity and its associated socio-economic and demographic determinants. The results suggest that several factors including age, gender, education, income, employment, obesity, and depression are associated with both single and multimorbidity. Income and smoking, may not be associated with having a single chronic disease, but are strongly associated with multimorbidity. The magnitudes of the coefficients seem to also be larger for multimorbidity compared to single chronic disease, signifying a higher likelihood of an association. To our knowledge, this is the first study in South Africa, which indicates these associations at a population level. The findings will be important to healthcare planning and decision making and may have an impact on the management of non-communicable diseases.

\section{Study strengths and limitations}

A major strength of this study was the use of data from a large nationally representative sample. This made it possible to examine relationships between multimorbidity 
Table 1 Descriptive statistics of variables used in the analysis

\begin{tabular}{|c|c|c|c|c|}
\hline & None & One & Two or more & Total \\
\hline Chronic diseases & $(n=9,195 ; 79 \%)$ & $(n=1,980 ; 17 \%)$ & $(n=463 ; 4 \%)$ & $(n=11,638)$ \\
\hline \multicolumn{5}{|l|}{ Gender } \\
\hline Male & $3,853(42 \%)$ & $586(30 \%)$ & 119 (26\%) & 4,558 (39\%) \\
\hline Female & $5,342(58 \%)$ & $1,394(70 \%)$ & 344 (74\%) & $7,080(61 \%)$ \\
\hline \multicolumn{5}{|l|}{ Race } \\
\hline African & 7,528 (82\%) & $1,463(74 \%)$ & 333 (72\%) & $9,324(80 \%)$ \\
\hline Coloured & $1,121(12 \%)$ & $339(17 \%)$ & 86 (19\%) & $1,546(13 \%)$ \\
\hline Asian/Indian & 106 (1\%) & $26(1 \%)$ & 15 (3\%) & 147 (1\%) \\
\hline White & 440 (5 \%) & $152(8 \%)$ & $29(6 \%)$ & $621(5 \%)$ \\
\hline \multicolumn{5}{|l|}{ Education } \\
\hline None & 1,142 (12\%) & $520(26 \%)$ & $124(27 \%)$ & $1,786(15 \%)$ \\
\hline Primary & 1,986 (22\%) & 707 (36\%) & 193 (42\%) & $2,886(25 \%)$ \\
\hline Secondary & 5,455 (59\%) & 648 (33\%) & 124 (27\%) & 6,227 (54\%) \\
\hline Tertiary & 612 (7\%) & $105(5 \%)$ & $22(5 \%)$ & 739 (6\%) \\
\hline \multicolumn{5}{|l|}{ Employment } \\
\hline Unemployed & $5,614(61 \%)$ & 1,391 (70\%) & $351(76 \%)$ & $7,356(63 \%)$ \\
\hline Employed & 3,581 (39\%) & $589(30 \%)$ & 112 (24\%) & 4,282 (37\%) \\
\hline \multicolumn{5}{|l|}{ Income (quintiles) } \\
\hline Quintile 1 & 1,752 (19\%) & $292(15 \%)$ & $37(8 \%)$ & $2,081(18 \%)$ \\
\hline Quintile 2 & 1,979 (22\%) & 426 (22\%) & $83(18 \%)$ & $2,488(21 \%)$ \\
\hline Quintile 3 & $2,060(22 \%)$ & 467 (24\%) & 143 (31\%) & $2,670(23 \%)$ \\
\hline Quintile 4 & $2,055(22 \%)$ & 505 (26\%) & $130(28 \%)$ & $2,690(23 \%)$ \\
\hline Quintile 5 & $1,349(15 \%)$ & $290(15 \%)$ & 70 (15\%) & $1,709(15 \%)$ \\
\hline \multicolumn{5}{|l|}{ Social assistance } \\
\hline No & $5,873(64 \%)$ & 809 (41\%) & 131 (28\%) & $6813(59 \%)$ \\
\hline Yes & $3,324(36 \%)$ & 1170 (59\%) & 331 (72\%) & 4825 (41\%) \\
\hline \multicolumn{5}{|l|}{ Residence } \\
\hline Urban & 4,198 (46\%) & 999 (50\%) & $236(51 \%)$ & $5,433(47 \%)$ \\
\hline Rural & 4,997 (54\%) & $981(50 \%)$ & 227 (49\%) & 6,205 (53\%) \\
\hline \multicolumn{5}{|l|}{ Smoking } \\
\hline No & 7,098 (77\%) & $1560(79 \%)$ & $379(82 \%)$ & $9036(78 \%)$ \\
\hline Yes & $2,098(23 \%)$ & $420(21 \%)$ & $84(18 \%)$ & $2602(22 \%)$ \\
\hline \multicolumn{5}{|l|}{ Obesity } \\
\hline Not obese & $7,172(78 \%)$ & $1,218(62 \%)$ & $238(51 \%)$ & $8,628(74 \%)$ \\
\hline Obese & $2,023(22 \%)$ & 762 (38\%) & $225(49 \%)$ & $3,010(26 \%)$ \\
\hline \multicolumn{5}{|l|}{ Health facility visits } \\
\hline No & $7,470(81 \%)$ & $888(45 \%)$ & $150(32 \%)$ & $8,508(73 \%)$ \\
\hline Yes & $1,725(19 \%)$ & $1,092(55 \%)$ & $313(68 \%)$ & $3,130(27 \%)$ \\
\hline \multicolumn{5}{|l|}{ Civic participation } \\
\hline No & $5,945(65 \%)$ & $1,224(62 \%)$ & $250(54 \%)$ & $7,419(64 \%)$ \\
\hline Yes & $3,250(35 \%)$ & 756 (38\%) & $213(46 \%)$ & $4,219(36 \%)$ \\
\hline
\end{tabular}

and various social determinants of health. However, the cross-sectional nature of the study limits the ability to draw causal inferences.
The study could have underestimated the prevalence of multimorbidity, since only a few chronic diseases were included. Further, the chronic diseases assessed in this 
study were reported by the respondents and not measured independently by an expert. While it is possible for respondents to know of their afflictions, this cannot be taken with the certainty that would be given if the diseases were measured objectively. Since the diseases were reported and not measured, it is difficult to judge whether the diseases present in an individual were active or relevant. As a result, there was no differentiation of the weight of the various diseases within an individual. The measure of multimorbidity was thus a count that did not take into account the intensity or severity of disease. The study also misses out on the hidden chronic diseases, which may be unknown to patients, and discovered only by expert diagnosis.

In this paper, we define multimorbidity as the coexistence of multiple diseases. This definition is made from a limited, medicalised perspective, which may not take into account the patients' understanding of their problems. A more wholistic definition is required to capture a representative view of disease. This, however, was not possible in this analysis given the way that data were collected in the SA-NIDS.

\section{Comparison with other studies}

Estimates of multimorbidity prevalence vary from country to country due to settings and definitions of multimorbidity. However, a recent systematic review of studies in developed countries by Fortin et al., indicated a prevalence rate ranging from $3.5 \%$ to $98.5 \%$ in primary care setting and $13.1 \%$ to $71.8 \%$ nationally [34]. In our study, the prevalence of multimorbidity was $4 \%$, with over $70 \%$ of adults with multimorbidity being females. Other studies also show that multimorbidity may be more common in females than males [35]. This finding warrants further investigations into gender differentials and the effects of gender-based inequities in the health sector in sub-Saharan African countries. Health inequalities

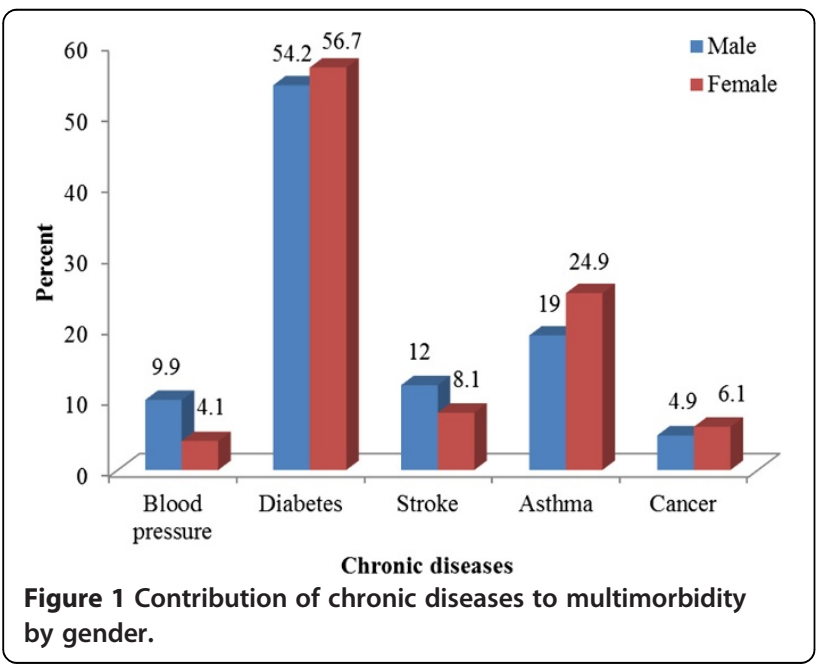

have been shown to exist in the South African population [23], as well as the gender disparities in health services utilisation and the associated health outcomes [36].

The study found a positive association between household income and multimorbidity (but not having a single chronic disease). This association remained strong, even after adjusting for other variables. Other studies have shown this relationship between household income and multimorbidity [27], but some show that the reverse is also true [37]. In many low and middle income countries, non-communicable diseases are shown to be present in individuals from affluent communities and well-to-do households, which are more likely to adopt Western lifestyles and diets [19].

Chronic diseases, both single and multimorbidity, were less common among educated and employed persons. Empirical population-based studies mostly from high income countries indicate that better educated individuals have less risk of chronic diseases such as cardiovascular diseases, as well as multimorbidity [38,39]. Improved education could reflect a better use of information that improves access to healthcare and also indirectly reduces behavioural risk factors [39]. Informal education, which happens at the family and community level, through interactions with others, is also a source of information that can have an impact on one's health status. Indeed, features of social organization, such as interpersonal trust, reciprocity norms, and engagements with community and neighbourhood, known as social capital, have been shown to be beneficial for health [40]. In our study, however, social capital was consistently not associated with health. Even though social capital (measured by network membership) has been found to play a significant role in an individual's well-being [40], its relationship with health outcomes varies from being protective in nature [41] to lack of an association [33] and even sometimes destructive [42]. Though not statistically significant, the paradox can be observed between social networks and multimorbidity where civic participation increased the odds of multimorbidity. However, the inconsistency in the nature of association between social capital and health outcomes observed across literature may be due to variations in definitions and measurements [43]. It should also be noted that the measure of social capital used in this study did not include family ties, which have been shown to be important to managing chronic diseases [20]. Future research should test for the effect of family ties, as this could have an impact on the occurrence of multimorbidity.

As expected, obesity was positively associated with multimorbidity. This reiterates the fact that obesity is an underlying risk factor for a number of chronic diseases and multimorbidity. Obesity should therefore be a 
Table 2 Logistic regression analyses of factors affecting multimorbidity

\begin{tabular}{|c|c|c|c|c|c|c|c|c|}
\hline & \multicolumn{2}{|c|}{ Step 1 - Unadjusted } & \multicolumn{2}{|c|}{ Step 2 - Structural } & \multicolumn{2}{|c|}{ Step 3 - Intermediary } & \multicolumn{2}{|c|}{ Step 4 - Full } \\
\hline & OR & $(95 \% \mathrm{Cl})$ & OR & $(95 \% \mathrm{Cl})$ & OR & $(95 \% \mathrm{Cl})$ & OR & $(95 \% \mathrm{Cl})$ \\
\hline \multicolumn{9}{|c|}{1 Chronic disease } \\
\hline Age & $1.06^{* *}$ & $(1.05,1.07)$ & $1.18^{* *}$ & $(1.14,1.21)$ & & & $1.15^{* *}$ & $(1.11,1.18)$ \\
\hline \multicolumn{9}{|l|}{ Gender } \\
\hline Male & 1 & & 1 & & & & 1 & \\
\hline Female & $1.76^{* *}$ & $(1.50,2.06)$ & $1.53^{* *}$ & $(1.30,1.80)$ & & & 1.18 & $(0.98,1.41)$ \\
\hline \multicolumn{9}{|l|}{ Race } \\
\hline African & & & 1 & & & & 1 & \\
\hline Coloured & $1.73^{* *}$ & $(1.35,2.20)$ & $1.38^{*}$ & $(1.00,1.90)$ & & & 1.33 & $(0.94,1.86)$ \\
\hline Asian/Indian & 1.18 & $(0.77,1.82)$ & 1.04 & $(0.57,1.89)$ & & & 0.87 & $(0.39,1.95)$ \\
\hline White & $2.07^{* *}$ & $(1.36,3.17)$ & 1.44 & $(0.87,2.40)$ & & & $1.80^{*}$ & $(1.10,2.94)$ \\
\hline \multicolumn{9}{|l|}{ Education } \\
\hline None & & & 1 & & & & 1 & \\
\hline Primary & 0.85 & $(0.65,1.11)$ & 1.24 & $(0.95,1.62)$ & & & $1.30^{*}$ & $(1.01,1.68)$ \\
\hline Secondary & $0.30^{* *}$ & $(0.24,0.38)$ & $0.74^{*}$ & $(0.55,0.99)$ & & & 0.79 & $(0.59,1.05)$ \\
\hline Tertiary & $0.46^{*}$ & $(0.24,0.86)$ & 0.73 & $(0.43,1.25)$ & & & 0.83 & $(0.48,1.43)$ \\
\hline \multicolumn{9}{|l|}{ Employment } \\
\hline Unemployed & & & & & & & 1 & \\
\hline Employed & $0.68^{* *}$ & $(0.58,0.79)$ & $0.70^{* *}$ & $(0.58,0.86)$ & & & $0.72^{* *}$ & $(0.58,0.90)$ \\
\hline \multicolumn{9}{|l|}{ Income } \\
\hline Quintile 1 & 1 & & 1 & & & & 1 & \\
\hline Quintile 2 & 1.16 & $(0.93,1.44)$ & 1.02 & $(0.81,1.29)$ & & & 1.03 & $(0.81,1.32)$ \\
\hline Quintile 3 & $1.30^{*}$ & $(1.03,1.66)$ & 1.20 & $(0.93,1.56)$ & & & 1.21 & $(0.93,1.59)$ \\
\hline Quintile 4 & $1.40^{*}$ & $(1.08,1.83)$ & $1.41^{*}$ & $(1.04,1.92)$ & & & $1.44^{*}$ & $(1.05,1.97)$ \\
\hline Quintile 5 & 1.32 & $(0.96,1.83)$ & 1.24 & $(0.87,1.77)$ & & & 1.20 & $(0.82,1.75)$ \\
\hline \multicolumn{9}{|c|}{ Social assistance } \\
\hline No & & & 1 & & & & 1 & \\
\hline Yes & $2.67^{* *}$ & $(2.25,3.17)$ & $1.48^{* *}$ & $(1.22,1.80)$ & & & $1.30^{*}$ & $(1.06,1.60)$ \\
\hline \multicolumn{9}{|l|}{ Residence } \\
\hline Urban & 1 & & 1 & & & & 1 & \\
\hline Rural & $0.80^{*}$ & $(0.66,0.97)$ & $0.65^{* *}$ & $(0.52,0.81)$ & & & $0.70^{* *}$ & $(0.58,0.85)$ \\
\hline \multicolumn{9}{|l|}{ Smoking } \\
\hline No & 1 & & & & 1 & & 1 & \\
\hline Yes & 0.86 & $(0.69,1.08)$ & & & 1.13 & $(0.91,1.41)$ & 0.97 & $(0.77,1.22)$ \\
\hline \multicolumn{9}{|l|}{ Obesity } \\
\hline Not obese & 1 & & & & 1 & & 1 & \\
\hline Obese & $2.82^{* *}$ & $(2.37,3.35)$ & & & $2.67^{* *}$ & $(2.21,3.23)$ & $1.74^{* *}$ & $(1.43,2.12)$ \\
\hline Depression & $1.05^{* *}$ & $(1.03,1.07)$ & & & $1.04^{* *}$ & $(1.02,1.05)$ & $1.03^{* *}$ & $(1.01,1.05)$ \\
\hline \multicolumn{9}{|l|}{ Health facility } \\
\hline No & 1 & & & & 1 & & 1 & \\
\hline Yes & $4.94^{* *}$ & $(4.02,6.08)$ & & & $4.56^{* *}$ & $(3.74,5.57)$ & $3.77^{* *}$ & $(3.09,4.60)$ \\
\hline \multicolumn{9}{|c|}{ Civic participation } \\
\hline No & 1 & & & & 1 & & 1 & \\
\hline Yes & 1.11 & $(0.94,1.30)$ & & & 1.01 & $(0.85,1.19)$ & 0.92 & $(0.77,1.10)$ \\
\hline
\end{tabular}


Table 2 Logistic regression analyses of factors affecting multimorbidity (Continued)

\begin{tabular}{|c|c|c|c|c|c|c|c|c|}
\hline \multicolumn{9}{|c|}{2 or more chronic diseases } \\
\hline Age & $1.08^{* *}$ & $(1.07,1.09)$ & $1.44^{* *}$ & $(1.32,1.57)$ & & & $1.38^{* *}$ & $(1.25,1.51)$ \\
\hline \multicolumn{9}{|l|}{ Gender } \\
\hline Male & 1 & & 1 & & & & 1 & \\
\hline Female & $2.44^{* *}$ & $(1.77,3.35)$ & $1.95^{* *}$ & $(1.39,2.73)$ & & & 1.17 & $(0.78,1.75)$ \\
\hline \multicolumn{9}{|l|}{ Race } \\
\hline African & 1 & & 1 & & & & 1 & \\
\hline Coloured & $1.82^{* *}$ & $(1.33,2.49)$ & 1.24 & $(0.82,1.87)$ & & & 1.43 & $(0.90,2.26)$ \\
\hline Asian/Indian & $2.94^{*}$ & $(1.07,8.04)$ & 2.13 & $(0.69,6.59)$ & & & 2.12 & $(0.59,7.53)$ \\
\hline White & $2.21^{*}$ & $(1.08,4.51)$ & 1.12 & $(0.41,3.06)$ & & & 1.92 & $(0.70,5.29)$ \\
\hline \multicolumn{9}{|l|}{ Education } \\
\hline None & 1 & & 1 & & & & 1 & \\
\hline Primary & 0.79 & $(0.55,1.13)$ & 1.23 & $(0.84,1.80)$ & & & 1.34 & $(0.92,1.97)$ \\
\hline Secondary & $0.27^{* *}$ & $(0.17,0.42)$ & 0.91 & $(0.56,1.48)$ & & & 0.98 & $(0.58,1.66)$ \\
\hline Tertiary & $0.18^{* *}$ & $(0.09,0.34)$ & 0.30 & $(0.08,1.16)$ & & & 0.40 & $(0.11,1.44)$ \\
\hline \multicolumn{9}{|l|}{ Employment } \\
\hline Unemployed & 1 & & 1 & & & & 1 & \\
\hline Employed & $0.48^{* *}$ & $(0.34,0.70)$ & $0.65^{*}$ & $(0.42,0.99)$ & & & 0.70 & $(0.46,1.07)$ \\
\hline \multicolumn{9}{|l|}{ Income } \\
\hline Quintile 1 & 1 & & 1 & & & & 1 & \\
\hline Quintile 2 & $2.80^{* *}$ & $(1.59,4.96)$ & $2.14^{*}$ & $(1.21,3.79)$ & & & $2.23^{*}$ & $(1.28,3.88)$ \\
\hline Quintile 3 & $3.48^{* *}$ & $(1.97,6.16)$ & $2.90^{* *}$ & $(1.63,5.16)$ & & & $3.02^{* *}$ & $(1.71,5.32)$ \\
\hline Quintile 4 & $3.14^{* *}$ & $(1.72,5.75)$ & $2.86^{* *}$ & $(1.53,5.33)$ & & & $2.89^{* *}$ & $(1.56,5.33)$ \\
\hline Quintile 5 & $3.02^{* *}$ & $(1.56,5.84)$ & $3.69^{* *}$ & $(1.74,7.81)$ & & & $3.17^{* *}$ & $(1.46,6.86)$ \\
\hline \multicolumn{9}{|c|}{ Social assistance } \\
\hline No & 1 & & 1 & & & & 1 & \\
\hline Yes & $5.66^{* *}$ & $(4.03,7.97)$ & $2.84^{* *}$ & $(1.88,4.30)$ & & & $2.35^{* *}$ & $(1.59,3.49)$ \\
\hline \multicolumn{9}{|l|}{ Residence } \\
\hline Urban & 1 & & 1 & & & & 1 & \\
\hline Rural & 0.78 & $(0.58,1.05)$ & $0.59 * *$ & $(0.42,0.82)$ & & & $0.65^{*}$ & $(0.46,0.93)$ \\
\hline \multicolumn{9}{|l|}{ Smoking } \\
\hline No & 1 & & & & 1 & & 1 & \\
\hline Yes & $0.49^{* *}$ & $(0.34,0.71)$ & & & 0.75 & $(0.50,1.12)$ & $0.61^{*}$ & $(0.38,0.96)$ \\
\hline \multicolumn{9}{|l|}{ Obesity } \\
\hline Not obese & 1 & & & & 1 & & 1 & \\
\hline Obese & $4.80^{* *}$ & $(3.53,6.52)$ & & & $4.28^{* *}$ & $(3.12,5.88)$ & $2.33^{* *}$ & $(1.60,3.39)$ \\
\hline Depression & $1.09^{* *}$ & $(1.05,1.13)$ & & & $1.07^{* *}$ & $(1.03,1.11)$ & $1.07^{* *}$ & $(1.02,1.11)$ \\
\hline \multicolumn{9}{|c|}{ Health facility visits } \\
\hline No & 1 & & & & 1 & & 1 & \\
\hline Yes & $8.05^{* *}$ & $(5.98,10.84)$ & & & $6.91^{* *}$ & $(5.07,9.43)$ & $5.14^{* *}$ & $(3.75,7.05)$ \\
\hline \multicolumn{9}{|c|}{ Civic participation } \\
\hline No & 1 & & & & 1 & & 1 & \\
\hline Yes & 1.28 & $(0.92,1.79)$ & & & 1.10 & $(0.78,1.56)$ & 1.03 & $(0.77,1.38)$ \\
\hline
\end{tabular}

** $p<0.001 ; * p<0.05 ;$ OR Odds ratio, $C l$ Confidence interval. 
serious public health concern because of its negative effects on the health system [10] especially in Africa [12]. We also found that healthcare utilisation was positively associated with multimorbidity. This might be the case, because people who consult more often might have more conditions diagnosed [44].

\section{Policy implications}

The study findings give important insight into socio-economic and demographic factors associated with multimorbidity in South Africa. With the on-going health sector reforms in the country, there is need for policy makers to consider the implications of multimorbidity on the health system and its impact on healthcare resources, particularly in the face of increasing obesity and a high burden of HIV/AIDS. This study provides useful information that can aid decision making and resource allocation for improved health outcomes. For instance, the association between education, employment and multimorbidity may imply that people with better individual economic capability could have more resources to take care of themselves and thereby reduce the risk of multiple chronic diseases regardless of their age. We have shown that obesity and depression are associated with chronic disease and multimorbidity. There is need to put in place measures that will encourage healthy lifestyle and living in the general population. Mental illness, which is often a neglected disease, should be brought to the fore, in order to address its negative impact.

\section{Conclusion}

Given the paucity of empirical research on the social determinants of health and multimorbidity in Africa, this study adds important evidence to the literature on this topical issue. Due to the fact that research, medicine and health care has frequently focused on single disease [45,46], not much is known about the correlates of multimorbidity in many low and middle income countries [47]. It is important though, to adequately document this evidence, because it could have implications on the way resources are distributed to produce better health outcomes. In our study, we show that though similar, the correlates of chronic disease may differ from those of multimorbidity. For example, income appears to be more relevant to multimorbidity, and addressing welfare issues may be crucial to reducing multimorbidity. There could also be a difference in the way several other factors relate with single disease and multimorbidity, based on the strength and magnitude of the associations. This should be investigated in future research on the factors affecting multimorbidity.

\section{Competing interest}

Both authors declare that they have no conflict of interest.

\section{Authors' contributions}

Both authors contributed to the conceptualization and development of the theoretical ideas. OA and LC performed the analysis, wrote, read and approved the final manuscript.

\section{Acknowledgments}

The authors wish to acknowledge the Southern Africa Labour and Development Research Unit (SALDRU) based at the University of Cape Town, School of Economics, which conducted the South African National Income Dynamics Study (SA-NIDS)

\section{Author details}

${ }^{1}$ Health Economics Unit, School of Public Health and Family Medicine, University of Cape Town, Cape Town, South Africa. ${ }^{2}$ Health Systems and Services Research Unit, Division of Community Health, Stellenbosch University, Cape Town, South Africa.

Received: 10 January 2013 Accepted: 26 May 2013

Published: 20 August 2013

\section{References}

1. Fortin M, Dubois MF, Hudon C, Soubhi H, Almirall J: Multimorbidity and quality of life: a closer look. Health Qual Life Outcomes 2007, 5:52

2. Schafer I, Hansen H, Schon G, Hofels S, Altiner A, Dahlhaus A, Gensichen J, Riedel-Heller S, Weyerer S, Blank WA, et al: The influence of age, gender and socio-economic status on multiydmorbidity patterns in primary care. First results from the multicare cohort study. BMC Health Serv Res 2012, 12(89): . doi:10.1186/1472-6963-12-89.

3. Britt HC, Harrison CM, Miller GC, Knox SA: Prevalence and patterns of multimorbidity in Australia. Med J Aust 2008, 189(2):72-77.

4. Barnett K, Mercer SW, Norbury M, Watt G, Wyke S, Guthrie B: Epidemiology of multimorbidity and implications for health care, research, and medical education: a cross-sectional study. Lancet 2012, 380(9836):37-43.

5. Fortin M, Bravo G, Hudon C, Vanasse A, Lapointe L: Prevalence of multimorbidity among adults seen in family practice. Ann Fam Med 2005, 3(3):223-228.

6. Aarts S, den Akker M, Bosma H, Tan F, Verhey F, Metsemakers J, van Boxtel $M$ : The effect of multimorbidity on health related functioning: temporary or persistent? Results from a longitudinal cohort study. J Psychosom Res 2012, 73(3):211-217

7. Glynn LG, Valderas JM, Healy P, Burke E, Newell J, Gillespie P, Murphy AW: The prevalence of multimorbidity in primary care and its effect on health care utilization and cost. Fam Pract 2011, 28(5):516-523.

8. McCormick WC, Boling PA: Multimorbidity and a Comprehensive Medicare Care-Coordination Benefit. J Am Geriatr Soc 2005, 53(12):2227-2228

9. Starfield B, Lemke KW, Bernhardt T, Foldes SS, Forrest CB, Weiner JP Comorbidity: implications for the importance of primary care in 'Case' management. Ann Fam Med 2003, 1(1):8-14

10. Salisbury C, Johnson L, Purdy S, Valderas JM, Montgomery AA: Epidemiology and impact of multimorbidity in primary care: a retrospective cohort study. Br J Gen Pract 2011, 61(582):e12-e21.

11. Khanam MA, Streatfield PK, Kabir ZN, Qiu C, Cornelius C, Wahlin A Prevalence and patterns of multimorbidity among elderly people in rural Bangladesh: a cross-sectional study. J Heal Popul Nutr 2011, 29(4):406-414.

12. Zeba AN, Delisle HF, Genevieve R, Boubacar S, Banza B: The double burden of malnutrition and cardiometabolic risk widens the gender and socioeconomic health gap: a study among adults in Burkina Faso (West Africa). Public Health Nutr 2012, 15(12):2210-2219.

13. Househam KC: Africa's Burden of disease: the university of cape town Sub-saharan africa centre for chronic disease. South Afr Med J 2010, 100(2):94-95.

14. Armstrong ME, Lambert MI, Sharwood KA, Lambert EV: Obesity and overweight in South African primary school children - the Health of the Nation Study. S Afr Med J 2006, 96(5):439-444

15. Parkin DM, Sitas F, Chirenje M, Stein L, Abratt R, Wabinga H: Part I: Cancer in Indigenous Africans-burden, distribution, and trends. Lancet Oncol 2008, 9(7):683-692.

16. de-Graft Aikins A, Unwin N, Agyemang C, Allotey P, Campbell C, Arhinful D: Tackling Africa's chronic disease burden: from the local to the global. Glob Heal 2010, 6(1):5. 
17. Mayosi BM, Lalloo AJFUG, Sitas F, Tollman SM, Bradshaw D: The burden of non-communicable diseases in South Africa. Lancet 2009, 374(9693):934-947.

18. Boyd CM, Fortin M: Future of multimorbidity research: How should understanding of multimorbidity inform health system design? Public Health Rev 2010, 32(2):451-474.

19. Steyn K, Damasceno A: Lifestyle and Related Risk Factors for Chronic Diseases. In 2nd edition Edited by Jamison DT, Feachem RG, Makgoba MW, Bos ER, Baingana FK, Hofman KJ, Rogo KO. Washington (DC): Disease and Mortality in Sub-Saharan Africa; 2006.

20. Taylor A, Price K, Gill T, Adams R, Pilkington R, Carrangis N, Shi Z, Wilson D: Multimorbidity - not just an older person's issue. Results from an Australian biomedical study. BMC Publ Health 2010, 10(1):718.

21. Nagel G, Peter R, Braig S, Hermann S, Rohrmann S, Linseisen J: The impact of education on risk factors and the occurrence of multimorbidity in the EPIC-Heidelberg cohort. BMC Publ Health 2008, 8:384.

22. Solar O, Irwin A: A conceptual framework for action on the social determinants of health. Social Determinants of Health Discussion Paper 2 (Policy and Practice). In.: WHO; 2010.

23. Ataguba J, Akazili J, Mclntyre D: Socioeconomic-related health inequality in South Africa: evidence from General Household Surveys. Int J Equity health 2011, 10(1):48.

24. Kawachi I, Kennedy B, Lochner K, Prothrow-Stith D: Social capital, income inequality and mortality. Am J Public Health 1997, 87(9):1491-1498.

25. Vogel I, Miksch A, Goetz K, Ose D, Szecsenyi J, Freund T: The impact of perceived social support and sense of coherence on health-related quality of life in multimorbid primary care patients. Chronic IIInes 2012, 8:296-307.

26. Leibbrandt M, Woolard I, De Villiers L: Methodology: Report on NIDS Wave 1 . In. Cape Town: University of Cape Town; 2009.

27. Agborsangaya CB, Lau D, Lahtinen M, Cooke T, Johnson JA: Multimorbidity prevalence and patterns across socioeconomic determinants: a crosssectional survey. BMC Publ Health 2012, 12:201.

28. Lim W-Y, Ma S, Heng D, Bhalla V, Chew S: Gender, ethnicity, health behaviour \& self-rated health in Singapore. BMC Publ Health 2007, 7(1):184.

29. Tomita A, Burns JK: A multilevel analysis of association between neighborhood social capital and depression: Evidence from the first South African National Income Dynamics Study. J Affect Disord 2012, 144(1-2):101-105.

30. Ades PA, Savage PD, Toth MJ, Schneider DJ, Audelin MC, Bunn JY, Ludlow $M$ : The influence of obesity and consequent insulin resistance on coronary risk factors in medically treated patients with coronary disease. Int J Obes 2008, 32(6):967-974.

31. Zhang W, O'Brien N, Forrest JI, Salters KA, Patterson TL, Montaner JSG, Hogg RS, Lima VD: Validating a Shortened Depression Scale (10 Item CES-D) among HIV-Positive People in British Columbia, Canada. PLoS One 2012, 7(7):e40793.

32. Kawachi I, Berkman LF: Social Ties and Mental Health. J Urban Health 2001, 78(3):458-467.

33. Kroenke CH, Kubzansky LD, Schernhammer ES, Holmes MD, Kawachi I: Social networks, social support, and survival after breast cancer diagnosis. J Clin Oncol 2006, 24(7):1105-1111.

34. Fortin M, Stewart M, Poitras ME, Almirall J, Maddocks H: A systematic review of prevalence studies on multimorbidity: toward a more uniform methodology. Ann Fam Med 2012, 10(2):142-151.

35. Gamma A, Angst J: Concurrent psychiatric comorbidity and multimorbidity in a community study: gender differences and quality of life. Eur Arch Psychiatry Clin Neurosci 2001, 251(Suppl 2):|143-46.

36. Cornell M, Myer L, Kaplan R, Bekker LG, Wood R: The impact of gender and income on survival and retention in a South African antiretroviral therapy programme. Trop Med Int Health 2009, 14(7):722-731.

37. Hudon C, Fortin M, Poitras ME, Almirall J: The relationship between literacy and multimorbidity in a primary care setting. BMC Fam Pract 2012, 13:33

38. Millar WJ, Wigle DT: Socioeconomic disparities in risk factors for cardiovascular disease. CMAJ 1986, 134(2):127-132.

39. Marengoni A, Winblad B, Karp A, Fratiglioni L: Prevalence of chronic diseases and multimorbidity among the elderly population in sweden. Am J Public Health 2008, 98(7):1198-1200.

40. Marmot M, Friel $\mathrm{S}$ : Global health equity: evidence for action on the social determinants of health. J Epidemiol Community Health 2008, 62(12):1095-1097.
41. Michael YL, Berkman LF, Colditz GA, Holmes MD, Kawachi I: Social networks and health-related quality of life in breast cancer survivors: a prospective study. J Psychosom Res 2002, 52(5):285-293.

42. Lin J, Si SX: Can guanxi be a problem? Contexts, ties, and some unfavorable consequences of social capital in China. Asia Pac J Manag 2010, 27:561-581.

43. Pahl R: Some sceptical comments on the relationship between social support and well-being. Leis Stud 2003, 22(4):357-368.

44. Perkins AJ, Kroenke K, Unutzer J, Katon W, Williams JW Jr, Hope C, Callahan CM: Common comorbidity scales were similar in their ability to predict health care costs and mortality. J Clin Epidemiol 2004, 57(10):1040-1048.

45. Tinetti ME, Fried TR, Boyd CM: Designing health care for the most common chronic condition-multimorbidity. JAMA 2012, 307(23).

46. Starfield B: Threads and yarns: weaving the tapestry of comorbidity. Ann Fam Med 2006, 4(2):101-103.

47. Tucker-Seeley R, Li Y, Sorensen G, Subramanian S: Lifecourse socioeconomic circumstances and multimorbidity among older adults. BMC Publ Health 2011, 11:313.

doi:10.1186/1475-9276-12-63

Cite this article as: Alaba and Chola: The social determinants of multimorbidity in South Africa. International Journal for Equity in Health 2013 12:63

\section{Submit your next manuscript to BioMed Central and take full advantage of:}

- Convenient online submission

- Thorough peer review

- No space constraints or color figure charges

- Immediate publication on acceptance

- Inclusion in PubMed, CAS, Scopus and Google Scholar

- Research which is freely available for redistribution 